\title{
Risk of Perforated Appendicitis in Patients with Hyperbilirubinemia
}

\author{
Mohammed Ibrahim ${ }^{1}$, Mohammed Alotaibi ${ }^{2}$, Fawzi Alharthi ${ }^{2}$, Bader Alzahrani ${ }^{* 2}$, Saad Alotaibi ${ }^{2}$, \\ Eyad Alfaqeh ${ }^{2}$, Raad Alsuwat ${ }^{2}$
}

${ }^{1}$ Department of Surgery, College of Medicine, Taif University, Ta'if, Saudi Arabia

${ }^{2}$ Medical Student, College of Medicine, Taif University, Ta'if, Saudi Arabia

*Corresponding author: Bader AL Zahrani; Badr1432@hotmail.com

Received 28 May 2021;

Accepted 12 June 2021;

Published 15 June 2021

\begin{abstract}
Background: One of common causes of abdominal pain that needs an urgent medical intervention is Acute Appendicitis (AA), Perforated appendicitis that result of hyperbilirubinemia, and relation with age. Methods: This is a retrospective cross-sectional study that will be performed in King Abdulaziz Specialist Hospital, Taif city in Saudi Arabia on the period from January 2018 to January 2020. Sample size of 197 is determined by World Health Organization (WHO) sample size calculator. Oral consent is taken from those patients. We include patients based on their age and gender. That is, we include ages from 10 years old to 60 years old. We also select both genders, male and female. Those patients may be presented with typical or atypical features of appendicitis. $\underline{\text { Result: }}$ Out of 197 participants $49.7 \%(\mathrm{n}=98)$ were male and $50.3 \%$ $(n=99)$ were female. $21.8 \%(n=43)$ aged less than 20 years, $54.3 \%(n=107)$ aged from 20 to 40 years and $23.9 \%(n=47)$ aged more than 40 years. About 31\% ( $n=61)$ had perforated appendix. a significant relationship between perforated appendix and age was found $(p-v a l u e=0.012)$, in addition to bilirubin level ( $\mathrm{p}$-value $=0.001$ ) respectively. $\underline{\text { Conclusion: }}$ Our local community. The majority of perforated appendix cases we found to be association with increase hyperbilirubinemia
\end{abstract}

Keywords: Hyperbilirubinemia, Appendicitis, Perforated.

\section{Introduction}

Acute appendicitis is one of common causes of abdominal pain which requires an emergency surgery ${ }^{[1]}$. Even though acute appendicitis needs instant medical action as its symptoms may suddenly develop over a very short period of time, the diagnosis of acute appendicitis clinically is still a challenge. That is, the diagnosis of acute appendicitis mainly depends on some naïve techniques such as obtaining a proper history of the patient or doing some physical examination. It would be very difficult for a healthcare practitioner to link the facts he/she obtained from the proper history or the physical examination with the symptoms the patient has. Thus, using such naïve techniques will increase the likelihood for a healthcare practitioner to fail in diagnosing the acute appendicitis disease correctly.

Other recent techniques for diagnosing acute appendicitis were proposed ${ }^{[2]}$. Kabir et al. showed in their recent research that laboratory tests, clinical scoring systems, and some imaging modalities can be used to improve the accuracy of the diagnosis. Laboratory tests includes White Cell Count (WCC) and CReactive Protein (CRP), and Granulocyte count and Proportion of Polymorphonuclear (PMN) cells. Clinical scoring systems include
Alvarado score, RIPASA score, and AIR score. Imaging modalities include ultrasound, MRI and CT scan ${ }^{[3]}$.

A significant problem when it comes to acute appendicitis is not only the late presentation but also the delay of diagnosing. Both may lead to appendix perforation, which is one of the significant complications of acute appendicitis that are associated with increase both morbidity and mortality ${ }^{[4]}$. There are many reasons that may cause acute appendicitis. Fecolith is the most common cause of obstruction of appendicular lumen. The other causes may include lymphoid tissue hypertrophy, tumors, fruit seeds, and vegetables ${ }^{[5]}$. As a result of obstruction, the gramnegative bacteria will multiply along with continues mucous and toxin secretion which lead to increased intraluminal pressure and appendicular distention. As a result, venous and lymphatic drainage get weaken, which leads to mucosal ischemia then perforation ${ }^{[6]}$. The portal circulation absorbs these toxins, which leads to hepatocyte damage thereby the level of bilirubin increased ${ }^{[7]}$. Some recent studies have shown that hyperbilirubinemia as predictive factor of perforated appendicitis ${ }^{[8,9]}$. Ghimire et al., reported that bilirubin should not be used to predict perforation in appendicitis ${ }^{[10]}$. In this study, we aim to investigate the feasibility of using hyperbilirubinemia to predict gangrenous/perforated appendicitis. 


\section{Methods}

This is a retrospective cross-sectional study that will be performed in King Abdulaziz Specialist Hospital, Taif city in Saudi Arabia on the period from January 2018 to January 2020. Sample size of 197 is determined by World Health Organization (WHO) sample size calculator. Oral consent is taken from those patients. We include patients based on their age and gender. That is, we include ages from 10 years old to 60 years old. We also select both genders, male and female. Those patients may be presented with typical or atypical features of appendicitis. We exclude other ages from our study. That is, we exclude patients under10 years old and above 60 years old. We also exclude patients who have hepatitis A, B, or C, or have hemolytic anemia. Patients who are on drugs are excluded. Meaning that any patient who uses hepatotoxic drug will not be considered in our study. All patients diagnosed with acute Appendicitis, proven to have perforated appendix, and diagnosed via diagnostic investigation such as complete blood count or serum total bilirubin will be included in our research. Those patients are randomly selected with no selection bias.
Statistical analysis: Data entry and statical analysis was be done by using statical package for the social science (SPSS) version 22.

\section{Results}

This study aimed to assess the relationship between hyperbilirubinemia and acute perforated appendicitis. 197 participants aged from 10 to 60 years were included in this study while participants aged below 10 and above 60 , participants with hepatitis and hemolytic anemia were excluded. Out of 197 participants $49.7 \%(\mathrm{n}=98)$ were male and $50.3 \%(\mathrm{n}=99)$ were female. $21.8 \%(n=43)$ aged less than 20 years, $54.3 \%(n=107)$ aged from 20 to 40 years and $23.9 \%(n=47)$ aged more than 40 years (Table 1). About 31\% $(n=61)$ had perforated appendix (Figure 1).

Chi-Square is used and there was no relationship between perforated appendix and gender, weight, or CRP level (p-values= $0.260,0.125,0.258$ ) respectively (Table 2 ). But a significant relationship between perforated appendix and age was found ( $\mathrm{p}$ value $=0.012)$, in addition to bilirubin level $(\mathrm{p}$-value $=0.001)$ respectively (Table 3).

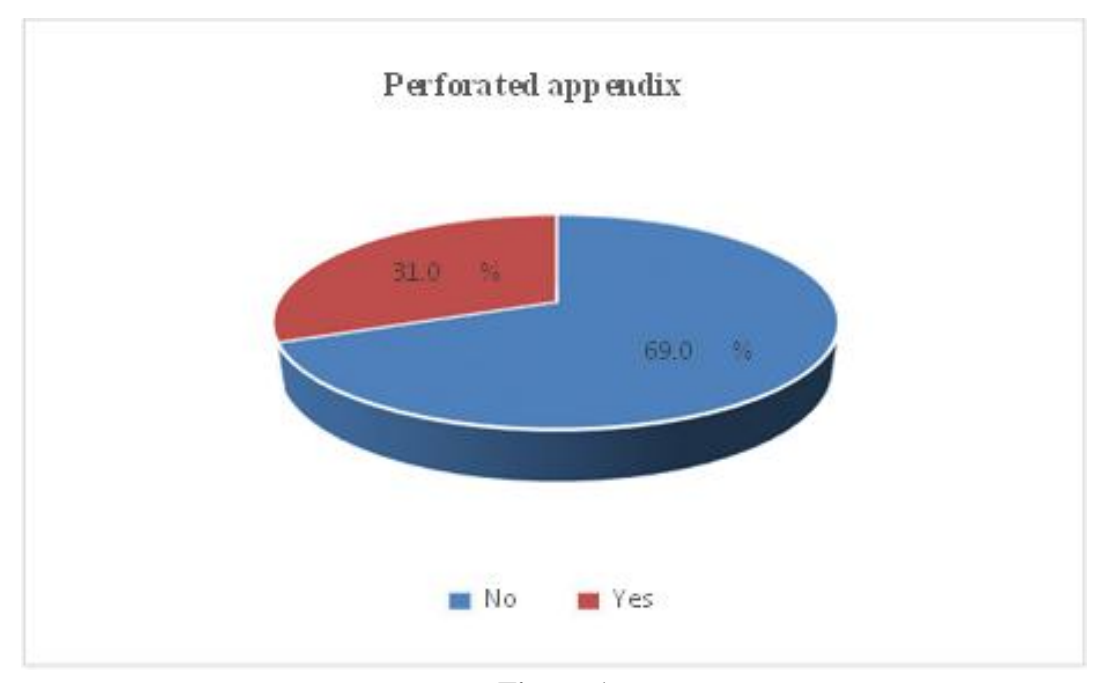

Figure 1

Table 1

\begin{tabular}{|c|c|c|c|}
\hline & & Count & $\%$ \\
\hline \multirow[t]{3}{*}{ Age } & Less than 20 Years & 43 & $21.8 \%$ \\
\hline & From 20 to 40 Years & 107 & $54.3 \%$ \\
\hline & More than 40 Years & 47 & $23.9 \%$ \\
\hline \multirow[t]{2}{*}{ Gender } & Female & 99 & $50.3 \%$ \\
\hline & Male & 98 & $49.7 \%$ \\
\hline
\end{tabular}

Table 2

\begin{tabular}{|c|c|c|c|c|c|c|}
\hline & & \multicolumn{2}{|c|}{ Perforated appendix } & \multirow{3}{*}{$\begin{array}{c}\text { Total } \\
99\end{array}$} & \multirow{4}{*}{$\begin{array}{c}\text { Pearson ChiSquare } \\
1.269\end{array}$} & \multirow{4}{*}{$\begin{array}{l}\text { Sig. } \\
0.260\end{array}$} \\
\hline & & No & Yes & & & \\
\hline \multirow[t]{2}{*}{ gender } & Female & 72 & 27 & & & \\
\hline & Male & 64 & 34 & 98 & & \\
\hline & & \multicolumn{2}{|c|}{ Perforated appendix } & Total & Pearson ChiSquare & Sig. \\
\hline & & No & Yes & & \multirow{4}{*}{4.162} & \multirow{4}{*}{0.125} \\
\hline \multirow[t]{3}{*}{ weight } & Less than $50 \mathrm{k.g}$ & 11 & 1 & 12 & & \\
\hline & From 50 to $90 \mathrm{k.g}$ & 108 & 55 & 163 & & \\
\hline & More than $90 \mathrm{k.g}$ & 17 & 5 & 22 & & \\
\hline & & \multicolumn{2}{|c|}{ Perforated appendix } & Total & \multirow[t]{2}{*}{ Pearson ChiSquare } & \multirow[t]{2}{*}{ Sig. } \\
\hline & & No & Yes & & & \\
\hline \multirow[t]{2}{*}{ CRP (mg/L) } & Normal & 32 & 10 & 42 & \multirow[t]{2}{*}{1.278} & \multirow[t]{2}{*}{0.258} \\
\hline & Non-Normal & 104 & 51 & 155 & & \\
\hline
\end{tabular}


Table 3

\begin{tabular}{|c|c|c|c|c|c|c|}
\hline & \multicolumn{2}{|c|}{ Perforated appendix } & \multirow[t]{2}{*}{ Total } & \multirow[t]{2}{*}{ Pearson ChiSquare } & \multirow[t]{2}{*}{ Sig. } \\
\hline & & No & Yes & & & \\
\hline \multirow[t]{5}{*}{ Age } & Less than 20 Years & 35 & 8 & 43 & \multirow[t]{3}{*}{8.791} & \multirow[t]{3}{*}{0.012} \\
\hline & From 20 to 40 Years & 76 & 31 & 107 & & \\
\hline & More than 40 Years & 25 & 22 & 47 & & \\
\hline & & \multicolumn{2}{|c|}{ Perforated appendix } & \multirow[t]{2}{*}{ Total } & \multirow[t]{2}{*}{ Pearson ChiSquare } & \multirow[t]{2}{*}{ Sig. } \\
\hline & & No & Yes & & & \\
\hline \multirow{2}{*}{$\begin{array}{l}\text { bilirubin level } \\
(\mathrm{mg} / \mathrm{dl})\end{array}$} & Normal & 124 & 36 & 160 & \multirow[t]{2}{*}{28.553} & \multirow[t]{2}{*}{0.001} \\
\hline & Non-normal & 12 & 25 & 37 & & \\
\hline
\end{tabular}

\section{Discussion}

The current study was retrospective cross-sectional study that was conducted to examine the relationship between hyperbilirubinemia and acute perforated appendicitis. The present study was conducted in King Abdulaziz Specialist Hospital on 197 Saudi participants aged from 10 to 60 years. Out of 197 participants $49.7 \%(n=98)$ were male and $50.3 \%(n=99)$ were female. $21.8 \%(n=43)$ aged less than 20 years, $54.3 \%(n=107)$ aged from 20 to 40 years and $23.9 \%$ $(n=47)$ aged more than 40 years.

The present study found that there was no relationship between perforated appendicitis and gender, weight, or CRP level $(p$-values $=0.260,0.125,0.258)$ respectively. These findings regarding relationship between perforated appendicitis and gender concurred with Ghimire et al (2012) and Estrada et al. (2007) who found no significant relationship between appendicitis and gender $(\mathrm{p}=0.284, \mathrm{p}=0.229)$. On the other hand, this study finding regarding the relationship between perforated appendicitis and CRP level was opposed by Ortega-Deballon et al (2008) who indicated that CRP values were significantly higher than those for patients with appendicitis $(\mathrm{p}=0.013)$. The difference in this study and OrtegaDeballon et al (2008) study regarding perforated appendicitis and CRP level could be caused by the design of the current study. The current study design was was a retrospective study which may have led to possible selection bias that could responsible for difference in this study and Ortega-Deballon et al (2008) findings regarding perforated appendicitis and CRP level (Estrada et al. 2007).

However, in this study, a significant relationship between perforated appendicitis and age was found $(\mathrm{p}$-value $=0.012)$. The current study finding regarding relationship between perforated appendicitis and age was contraindicated by Estrada et al. (2007) and Ghimire et al (2012) who found no significant relationship between appendicitis and age $(\mathrm{p}=0.95, \mathrm{p}=0.342)$. Furthermore, a significant relationship between perforated appendicitis and bilirubin level $(\mathrm{p}$-value $=0.001)$. The previous finding agrees with Ghimire et al (2012) who concluded that statistically significant relationship was found between appendicitis and bilirubin level $(\mathrm{p}=$ $<0.001)$.

The difference between the present study findings and other studies discussed in the section indicate the importance of further studies to be conducted. This study concludes that more rigorous research studies with larger sample sizes need to be undertaken to investigate the relationship between hyperbilirubinemia and acute perforated appendicitis.

\section{Conclusion}

Our local community: The majority of perforated appendix cases we found to be association with increase hyperbilirubinemia

\section{Ethics approval}

This study was approved by the institutional review board from the research center in Taif University, Ta'if, Saudi Arabia

\section{Conflicts of Interest}

The authors have no conflicts of interest to declare.

\section{Source of Funding}

This study did not receive any specific grant from funding agencies in the public, commercial, or not-for-profit sectors.

\section{Reference}

[1] Petroianu A. Diagnosis of acute appendicitis. Int J Surg. 2012;10(3):115-9

[2] Kabir SA, Kabir SI, Sun R, Jafferbhoy S, Karim A. How to diagnose an acutely inflamed appendix; a systematic review of the latest evidence. Int J Surg. 2017;40:155-62.

[3] Debnath J, Kumar R, Mathur A, Sharma P, Kumar N, Shridhar N, et al. On the Role of Ultrasonography and CT Scan in the Diagnosis of Acute Appendicitis. Indian J Surg 2015;77(Suppl 2): S221-6.

[4] Scher KS, Coil JA. The continuing challenge of perforating appendicitis.Surg GynecolObstet 1980; 150:535-8.

[5] Jaffe BM, Berger DH. The appendix. Schwartz's principles of surgery. 9th ed. New York: McGraw Hill; 2010. pp. 1073-1091.

[6] Maa J, Kirkwood KS. The Appendix. Sabiston textbook of surgery. 18th ed. 2008. pp. 1333-1347.

[7] Estrada JJ, Petrosyan M, Barnhart J, Tao M, Sohn H, Towfigh S, Mason RJ. Hyperbilirubinemia in appendicitis: a new predictor of perforation. Journal of gastrointestinal surgery. 2007 Jun 1;11(6):714-8.

[8] Gronroos JM, Gronroos P. Leucocyte count and Creactive protein in the diagnosis of acute appendicitis. $\mathrm{Br}$ J Surg. 1999;86:501-4.

[9] Ortega-Deballon P, Ruiz de Adana-Belbel JC, Hernandez-Matias A, et al. Usefulness of laboratory data in the management of right iliac fossa pain in adults. Dis Colon Rectum. 2008;51:1093-9.

[10] Ghimire P, Thapa P, Yogi N, et al. Role of serum bilirubin as a marker of acute gangrenous appendicitis. NJMS. 2012;1(2):89-92 